
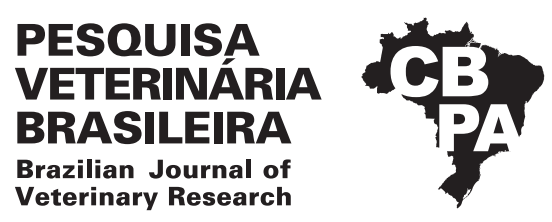

Pesq. Vet. Bras. 38(8):1638-1648, agosto 2018 DOI: 10.1590/1678-5150-PVB-5578

Original Article

ISSN 0100-736X (Print)

ISSN 1678-5150 (Online)

\title{
Mielodisplasia na peritonite infecciosa felina: 16 casos $(2000-2017)^{1}$
}

\author{
Flávia S. Luz², Renata D. Mazaro², Douglas M. Lorensetti³ ${ }^{3}$ Glaucia D. Kommers ${ }^{4}$, \\ Mariana M. Flores ${ }^{4}$ e Rafael A. Fighera ${ }^{4 *}$
}

\begin{abstract}
Luz F.S., Mazaro R.D., Lorensetti D.M., Kommers G.D., Flores M.M. \& Fighera R.A. 2018. [Myelodysplasia in feline infectious peritonitis: 16 cases (2000-2017).] Mielodisplasia na peritonite infecciosa felina: 16 casos (2000-2017). Pesquisa Veterinária Brasileira 38(8):16381648. Departamento de Patologia, Universidade Federal de Santa Maria, Av. Roraima 1000, Santa Maria, RS 97105-900, Brazil. E-mail: anemiaveterinaria@yahoo.com.br

Although the prevalence of feline infectious peritonitis (FIP) is high worldwide, recent anatomopathological studies about this disease are scarce. Information on the microscopic characteristics of the bone marrow in FIP-affected cats are absent in the available literature. Based on this, the purpose of this article is to describe bone marrow lesions seen in spontaneous cases of FIP. The bone marrow collected systematically from the femoral diaphysis of 16 cats necropsied in the Laboratory of Veterinary Pathology (LPV) of the Federal University (UFSM) of Southern Brazil, between January 2000 and June 2017, with a definitive diagnosis of FIP, were evaluated phenotypically (histopathology - hematoxylin and eosin and histochemistry - Perls stain) and immunophenotypically (immunohistochemistry using myeloid - Anti-MAC387, and lymphocytic - Anti-CD79 acy and Anti-CD3 markers). Regardless the following was observed the clinicopathological form of the disease ("dry" - noneffusive or "wet" - effusive): 1) myeloid hyperplasia; 2) erythroid hipoplasia; 3) megakaryocytic dysplasia (dismegakaryocytopoiesis); and 4) medullary plasmacytosis. Exclusively in cases of "dry FIP" was bone marrow and hepatic hemosiderosis. These lesions allowed establishing that cats with FIP develop myelodysplasia, a myeloproliferative lesion very similar to that reported in HIV-infected humans. It is suggested that, based on the findings described here, myelodysplasia is considered to be the main cause of hematological abnormalities observed in FIP, especially for non-regenerative anemia and thrombocytopenia, frequently developed by patients.
\end{abstract}

INDEX TERMS: Myelodysplasia, feline, infectious peritonitis, myeloid hyperplasia, erythroid hipoplasia, megakaryocytic dysplasia, diseases of cats, cats, pathology.

RESUMO.- Apesar da prevalência da peritonite infecciosa felina (PIF) ser alta em praticamente o mundo todo, estudos anatomopatológicos recentes acerca dessa doença são escassos. Não obstante, as características microscópicas

\footnotetext{
${ }^{1}$ Recebido em 21 de agosto de 2017.

Aceito para publicação em 20 de setembro de 2017.

${ }^{2}$ Programa de Pós-Graduação em Medicina Veterinária, área de concentração em Patologia e Patologia Clínica Veterinária, Centro de Ciências Rurais (CCR), Universidade Federal de Santa Maria (UFSM), Avenida Roraima 1000, Camobi, Santa Maria, RS 97105-900, Brasil. *Autor para correspondência: anemiaveterinaria@yahoo.com.br

${ }^{3}$ Bolsista PIBIC/CNPq/UFSM, Curso de Medicina Veterinária, Centro de Ciências Rurais (CCR), Universidade Federal de Santa Maria (UFSM), Avenida Roraima 1000, Camobi, Santa Maria, RS 97105-900.

${ }^{4}$ Departamento de Patologia, Centro de Ciências da Saúde (CCS), Universidade Federal de Santa Maria (UFSM), Av. Roraima 1000, Camobi, Santa Maria, RS 97105-900.
}

da medula óssea de gatos com PIF estão ausentes da literatura consultada. 0 objetivo deste artigo é descrever alterações medulares ósseas vistas em casos espontâneos de PIF. As medulas ósseas colhidas sistematicamente da região diafisária dos fêmures de 16 gatos necropsiados no Laboratório de Patologia Veterinária (LPV) da Universidade Federal de Santa Maria (UFSM), Rio Grande do Sul, entre janeiro de 2000 e junho de 2017, e que tiveram diagnóstico definitivo de PIF, foram avaliadas fenotípica (histopatologia - hematoxilina e eosina e histoquímica - reação de Perls) e imunofenotipicamente (utilizando marcadores mieloides (anti-MAC387) e de linfócitos (anti-CD79 $\alpha$ cy e anti-CD3). Os resultados permitem afirmar que, independentemente da apresentação clinicopatológica da doença ocorrem as seguintes alterações: 1) hiperplasia mieloide; 2) hipoplasia eritroide, 3) displasia megacariocítica (dismegacariocitopoiese) e 
4) plasmocitose medular. Exclusivamente nos casos de PIF seca há hemossiderose medular óssea e hepática. Essas alterações permitem estabelecer que gatos com PIF desenvolvem mielodisplasia, uma lesão mieloproliferativa muito semelhante àquela relatada em humanos infectados pelo HIV. Sugere-se que a partir dos achados aqui descritos, a mielodisplasia seja considerada a principal responsável pelas alterações hematológicas observadas na PIF, especialmente pela anemia e trombocitopenia arregenerativas frequentemente desenvolvidas pelos pacientes com essa doença.

TERMOS DE INDEXAÇ̃̃O: Mielodisplasia, peritonite infecciosa, hiperplasia mieloide, hipoplasia eritroide, displasia megacariocítica, doenças de gatos, felinos, patologia.

\section{INTRODUÇÃo}

A peritonite infecciosa felina (PIF) é uma doença viral altamente contagiosa, progressiva e invariavelmente fatal que acomete gatos e, ocasionalmente felídeos selvagens; decorre de reações de hipersensibilidade mediada por anticorpos (tipos III e IV), em um indivíduo incapaz de montar uma resposta imune celular normal (Addie 2015). Independentemente de sua forma de apresentação (seca - não efusiva ou úmida - efusiva), a anemia é uma das apresentações clinicopatológicas mais prevalentes em vários estudos (Norris et al. 2005, Tsai et al. 2011, Riemer et al. 2016). Para a maior parte dos autores (Stockham 2000), anemia em gatos com PIF ocorre pelo clássico mecanismo de sequestro de ferro, sendo, portanto, considerada uma anemia de doenças crônicas (anemia da doença inflamatória crônica ou anemia paradoxal). Além disso, os pacientes afetados comumente apresentam leucocitose por neutrofilia e trombocitopenia (Jain 1986). Apesar de todos esses achados hematológicos, PIF é considerada uma polisserosite (Uzal et al. 2016). Manifestações neurológicas, oftalmológicas, renais, dentre outras, refletem o caráter multissistêmico da doença (Addie 2015). Entretanto, por mais que achados clássicos de disfunção hematopoiética sejam marcadamente prevalentes, raros são os estudos que avaliaram órgãos do sistema hematopoiético em gatos acometidos pela condição. Dessa forma, devido à PIF ser uma doença muito prevalente em gatos na Região Central do Rio Grande do Sul, não haver nenhum artigo científico na literatura acerca das características anatomopatológicas da medula óssea na PIF e, frequentemente o paciente manifestar os achados hematológicos previamente citados, principalmente anemia e trombocitopenia, de origem pouco compreendida, é oportuno descrever as possíveis alterações medulares vistas em casos espontâneos de PIF.

\section{MATERIAL E MÉTODOS}

Os casos de PIF incluídos neste estudo ocorreram entre janeiro de 2000 e junho de 2017, no Município de Santa Maria (29³2'52" e $53^{\circ} 42^{\prime} 10^{\prime \prime}$ WGR). Foram considerados apenas casos diagnosticados através de critérios anatomopatológicos e que foram necropsiados no Laboratório de Patologia Veterinária da Universidade Federal de Santa Maria (LPV-UFSM). Para isso, os laudos de necropsias de gatos, realizadas no referido período, foram revisados em busca de casos da doença. Incluíram-se apenas os casos em que os tecidos colhidos e processados rotineiramente para histopatologia eran disponíveis em blocos de parafina no Arquivo de Blocos do LPV-UFSM. Todos esses casos foram validados macroscopicamente por meio da associação das imagens das lesões macroscópicas do Arquivo do LPV-UFSM e a histopatologia. Para isso, novas lâminas foram confeccionadas a partir dos tecidos incluídos em parafina, corados pela hematoxilina-eosina (HE) e reavaliados por três observadores. 0 diagnóstico definitivo do caso como PIF foi estabelecido utilizando os seguintes critérios, conforme Uzal et al. 2016: presença de piogranulomas em diferentes órgãos, mas principalmente rins, fígado, pâncreas, pulmão, olho e/ou sistema nervoso central (PIF seca) ou ocorrência de serosites (peritonite, pleurite, pericardite, sinovite e/ou meningite) fibrinosas associadas a vasculite ou perivasculite (PIF úmida) ou uma mistura dessas lesões (PIF mista).

A medula óssea oriunda da região diafisária dos fêmures foi reavaliada e a proporção entre o tecido ativo (hematopoiético) e o tecido inativo (gordura) foi estabelecida apenas através do critério visual proporcional em cinco grupos: 0\% (ausência de tecido hematopoiético), 25\%, 50\%, 75\% e 100\% (ausência de gordura). No tecido hematopoiético, as células foram identificadas como pertencentes aos compartimentos mieloide (linhagens granulocítica e monocítica), eritroide, megacariocítico e linfoide. Para determinar a proporção exata de cada compartimento mieloide utilizou-se, além do critério fenotípico (histopatologia), os achados imunofenotípicos (imuno-histoquímica). 0 marcador empregado foi o anticorpo monoclonal anti-antígeno mieloide/histiocítico humano (Mac 387) produzido em camundongo. Para determinar a população de linfócitos foi utilizada a mesma metodologia, porém com anticorpo monoclonal anti-antígeno CD79 $\alpha$ cy humano produzido em camundongo e anticorpo policlonal anti-antígeno CD3 humano produzido em coelho. Os compartimentos eritroide e megacariocítico foram determinados por exclusão dos demais, através da morfologia característica de suas células e da não imunomarcação pelos anticorpos previamente descritos. Os protocolos das três técnicas são relativamente semelhantes e estão descritos no próximo parágrafo deste Material e Métodos. Eles são utilizados como padrão para a técnica no Serviço de Imuno-histoquímica do LPV-UFSM. 0 volume ocupado por cada um dos compartimentos foi demonstrado em cruzes, sendo: + (mínima quantidade de células); ++ (pequena quantidade de células); +++ (moderada quantidade de células); ++++ (grande quantidade de células); e +++++ (máxima quantidade de células). Conforme a literatura tradicional em hematopatologia, compartimentos com quantidade de células precursoras abaixo ou acima do normal foram denominados como hipoplásicos e hiperplásicos, respectivamente. Quanto ao número de blastos, consideraram-se os valores atuais estabelecidos pela Organização Mundial da Saúde (OMS), em que até $6 \%$ do total de células nucleadas (TCN), o compartimento é denominado hiperplásico, a partir de 7\% do TCN, o compartimento é considerado displásico (distúrbio mieloproliferativo crônico [DMC]), e a partir de $20 \%$ do TCN, o compartimento é considerado neoplásico (leucemia mieloide aguda [LMA]). Para definição de blasto, observaram-se os critérios descritos por Bain 2003, em que: "Blasto é uma célula hematopoiética precursora imatura com alta relação núcleo-citoplasmática, citoplasma variavelmente basofílico e núcleo formado por cromatina frouxa com pelo menos um nucléolo evidente". 0 grau de maturação dos diferentes compartimentos foi estabelecido conforme as limitações inerentes da técnica empregada (histopatologia). Os dados hematológicos e epidemiológicos a cerca de cada caso foram obtidos a partir da revisão dos laudos de necropsia, incluindo suas respectivas requisições e, quando possível, das fichas de atendimento arquivadas no Serviço de Arquivos Veterinário (SAVE) do Hospital Veterinário Universitário da UFSM (HVU-UFSM). 
A técnica de imuno-histoquímica (IHQ) empregada foi a imunomarcação para células do compartimento mieloide (linhagens granulocítica e monocítica - com anticorpo anti-MAC 387), para linfócitos $\mathrm{T}$ e seus precursores (com anticorpo anti-CD3) e para linfócitos B, plasmócitos e seus precursores (com anticorpo anti-CD79 $\alpha$ cy), conforme protocolo descrito a seguir. Fragmentos de medula óssea embebidos em parafina foram recortados entre 3 e 5 micrômetros de espessura e depositados em lâminas silanizadas Após a desparafinização e reidratação, foi realizado o bloqueio das peroxidases endógenas com peróxido de hidrogênio comercial a 3\% por dois tempos de 10 minutos. A recuperação antigênica foi feita com solução de Tris-EDTA (pH 9,0) no forno de micro-ondas, na potência alta, por 10 minutos. 0 bloqueio das reações inespecíficas foi realizado com o bloqueador de proteínas (EasyPath) por 10 minutos em temperatura ambiente. Como anticorpo primário foram utilizados os monoclonais anti-MAC387, anti-CD79 $\alpha$ cy e anti-CD3 humanos produzidos em camundongo e coelho, respectivamente. Tais anticorpos foram diluídos em PBST na seguinte proporção: 1:200 para o anticorpo anti-CD79 $\alpha$ cy, 1:500 para o anticorpo anti-MAC387 e 1:400 para o anticorpo anti-CD3. Após a diluição, foram incubados em estufa a $37^{\circ} \mathrm{C}$ por 60 minutos. 0 anticorpo secundário (polímero) foi utilizado consecutivamente, incubado em temperatura ambiente por 20 minutos e marcado através da adição do cromógeno de tetracloreto de 3-3' diaminobenzidina (DAB) por 3 minutos para o anticorpo anti-MAC387 e por 5 minutos para os anticorpos anti-CD79 $\alpha$ cy e anti-CD3. As lavagens entre as etapas da técnica foram feitas com PBST em pH 7,6. A contra-coloração foi realizada com hematoxilina de Harris. Tonsilas e linfonodos mesentéricos de gatos foram utilizados como controle positivo. Como controle negativo, as mesmas secções foram utilizadas, com substituição do anticorpo primário por PBST. Foram considerados como linfócitos B (incluindo plasmócitos) e seus precursores, todas as células imunomarcadas para CD79 $\alpha$ cy, mas não para CD3 ou MAC387; como linfócitos T e seus precursores, todas as células imunomarcadas para CD3, mas não para CD79 $\alpha$ cy ou MAC387; e como células do compartimento mieloide (linhagens granulocítica e monocítica) todas as células imunomarcadas para MAC387, mas não para CD79 $\alpha$ cy e CD3. Células não imunomarcadas para nenhum dos anticorpos foram consideradas como outras, não pertencentes aos compartimentos granulocítico-monocítico ou linfoide, ou seja, basicamente aquelas pertencentes aos compartimentos eritroide e megacariocítico.

Para determinar a presença de ferro tecidual e realizar sua quantificação foi utilizado o método de Perls, que consiste na reação do ferro férrico presente no tecido analisado com o ferrocianeto de potássio (Reagente A) e o ácido clorídrico (Reagente B). Para isso, fragmentos de medula óssea e fígado embebidos em parafina foram recortados entre 3 e 5 micrômetros de espessura, depositados em lâminas, desparafinizados e reidratados. Uma solução obtida a partir da mistura de equivalente proporção dos reagentes A e B foi aplicada sobre o tecido, deixando agir por 60 minutos em temperatura ambiente. Após lavagem com água destilada, os cortes foram contracorados com Carmalumen de Mayer (Reagente $\mathrm{C}$ ) por 2 minutos à temperatura ambiente. Foram consideradas positivas para ferro as medulas ósseas em que células (macrófagos e precursores eritroides) demonstraram citoplasma de aspecto granular e corado com azul da Prússia. Foram considerados positivos para ferro os fígados em que células (células de Kupffer e hepatócitos) demonstraram citoplasma igualmente corado com azul da Prússia.

\section{RESULTADOS}

Entre janeiro de 2000 e junho de 2017 foram diagnosticados 57 casos de peritonite infecciosa felina (PIF) na rotina de necropsias do LPV-UFSM. Desses, apenas 16 tiveram a medula óssea colhida da região diafisária dos fêmures. Em todos os casos em que as medulas ósseas foram reavaliadas ( $\mathrm{n}=16$ ) havia aumento na quantidade de tecido hematopoiético e redução do percentual de gordura. Essa relação está expressa caso a caso no Quadro 1. 0 tecido hematopoiético era constituído principalmente de precursores das células sanguíneas dos compartimentos mieloide (linhagens granulocítica e monocítica) e megacariocítico. O compartimento eritroide estava sub-representado em todos os casos. 0 volume ocupado por cada compartimento e a relação mieloide:eritroide proporcional de cada caso podem ser vislumbrados no Quadro 1. Em relação ao compartimento mieloide havia células em todas as fases de proliferação (Fig.1), mas o escalonamento era anormal, com percentagens de blastos (mieloblastos/monoblastos) sempre marcadamente elevada (Fig.2), ausência ou diminuição acentuada no número de pró-mielócitos e variável quantidade precursores mieloides mais maduros (bastonetes, metamielócitos e mielócitos). A proporção entre essas células em cada caso está demonstrada no Quadro 2. Precursores eritroides (normoblastos) eram escassos e, quando observados, eram predominantemente rubrícitos e metarrubrícitos. Rubriblastos e pré-rubrícitos eram raros. Megacariócitos foram observados com frequencia e eram marcadamente abundantes em muitos casos (Fig.3). Precursores de megacariócitos também eram comuns, principalmente pré-megacariócitos. Muitos megacariócitos apresentavam critérios fenotípicos para serem incluídos como displásicos, tais achados incluíam principalmente: multilobulação (Fig.4), dislobulação e presença de núcleos em forma de chifre de veado (staghorn megacaryocyte) (Fig.5). Megacarioblastos não puderam ser diferenciados de outros blastos mieloides. 0 tecido linfoide medular estava mínimo a levemente aumento e era constituído exclusivamente de plasmócitos (Fig.6). Tais células dispunham-se de maneira

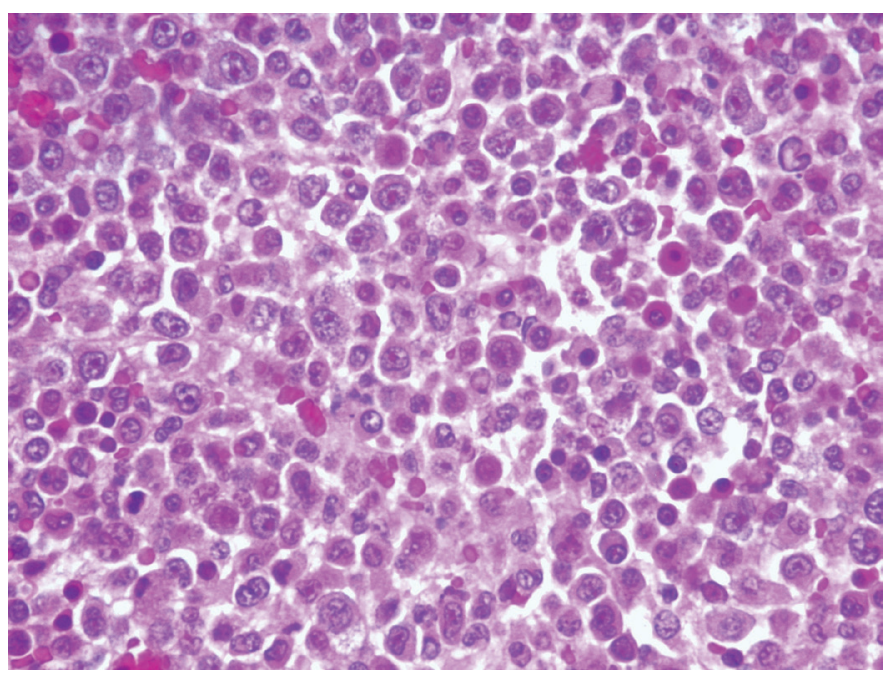

Fig.1. Peritonite infecciosa felina, medula óssea, gato. Tecido hematopoiético ativo sem nenhuma gordura presente. Note a alta relação mieloide:eritroide. HE, obj.20x. 
Quadro 1. Compartimentos da medula óssea de gatos com peritonite infecciosa felina

\begin{tabular}{|c|c|c|c|c|c|c|c|c|c|c|}
\hline Caso & Forma & Gênero & Raça & Idade & $\mathrm{TH}^{\mathrm{b}}$ & $\begin{array}{l}\text { Compart. } \\
\text { mieloide }^{c}\end{array}$ & $\begin{array}{l}\text { Compart. } \\
\text { eritroide }^{\mathrm{d}}\end{array}$ & Relação M:E & $\begin{array}{c}\text { Compart. } \\
\text { megacariocítico }\end{array}$ & $\begin{array}{l}\text { Compart. } \\
\text { linfoide }^{g}\end{array}$ \\
\hline Vn-236-00 & úmida & fêmea & Persa & 9 meses & $25 \%$ & $++^{*}$ & + & $2 \mathrm{x}$ & +++ & + \\
\hline Vn-235-01 & seca & macho & Siamês & IDT $^{\mathrm{a}}$ & $75 \%$ & +++++ & + & $5 x$ & +++++ & + \\
\hline Vn-331-02 & úmida & macho & Persa & 9 meses & $100 \%$ & ++++ & ++ & $2 \mathrm{x}$ & +++++ & + \\
\hline Vn-210-04 & úmida & macho & Persa & 8 meses & $75 \%$ & ++++ & + & $4 \mathrm{x}$ & +++++ & + \\
\hline Vn-256-04 & úmida & macho & Persa & 2 anos & $75 \%$ & +++++ & + & $5 x$ & +++++ & ++ \\
\hline Vn-164-06 & seca & macho & SRD & 4 meses & $50 \%$ & ++ & + & $2 \mathrm{x}$ & +++++ & + \\
\hline Vn-327-11 & úmida & macho & SRD & 2 anos & $50 \%$ & ++ & + & $2 \mathrm{x}$ & +++++ & + \\
\hline Vn-312-12 & úmida & macho & SRD & 2 anos & $50 \%$ & +++++ & ++ & $2,5 x$ & +++++ & + \\
\hline Vn-337-14 & seca & macho & SRD & 1 ano & $25 \%$ & ++ & + & $2 \mathrm{x}$ & +++++ & + \\
\hline Vn-343-15 & úmida & fêmea & SRD & 1 ano & $50 \%$ & ++++ & ++ & $2 \mathrm{x}$ & +++++ & + \\
\hline Vn-085-16 & seca & macho & SRD & 3 anos & $100 \%$ & +++++ & + & $5 x$ & ++ & ++ \\
\hline Vn-208-16 & seca & macho & SRD & 15 anos & $25 \%$ & +++ & ++ & $1,5 \mathrm{x}$ & ++ & ++ \\
\hline Vn-384-16 & seca & macho & SRD & 2 anos & $75 \%$ & +++++ & + & $5 x$ & +++ & + \\
\hline Vn-065-17 & úmida & macho & SRD & 1 ano & $50 \%$ & +++++ & + & $5 x$ & +++++ & ++ \\
\hline Vn-067-17 & mista & macho & SRD & 1 ano & $75 \%$ & +++++ & + & $5 x$ & +++++ & + \\
\hline Vn-172-17 & úmida & fêmea & SRD & 4 meses & $100 \%$ & +++++ & + & $5 x$ & +++++ & ++ \\
\hline
\end{tabular}

${ }^{a}$ IDT = idade desconhecida pelo tutor, ${ }^{b} \mathrm{TH}=$ proporção estabelecida entre o tecido hematopoiético (medula óssea ativa) e a gordura (medula óssea inativa), ${ }^{\mathrm{c}}$ Compartimento mieloide inclui mieloblastos, monoblastos, pró-mielócitos, pró-monócitos, mielócitos, metamielócitos, bastonetes, neutrófilos, eosinófilos, basófilos e monocitos, ${ }^{d}$ Compartimento eritroide inclui rubriblastos, pré-rubrícitos, rubrícitos e metarrubrícitos, ${ }^{e}$ Relação estabelecida entre os compartimentos mieloide e eritroide; expressa em número de vezes no qual um é maior que o outro, ${ }^{\mathrm{f}}$ Compartimento megacariocítico inclui megacarioblastos, pré-megacariócitos e megacariocitos, ${ }^{\mathrm{g}}$ Compartimento linfoide inclui linfócitos B (e plasmócitos) e seus precursores, mas não linfócitos T e seus precursores; * Escala de volume ocupado por cada compartimento hematopoiético na medula óssea, sendo + mínima quantidade de células, ++ pequena quantidade de células, +++ moderada quantidade de células, ++++ grande quantidade de células, +++++ máxima quantidade de células.

Quadro 2. Distribuição das células do compartimento mieloide de gatos com peritonite infecciosa felina

\begin{tabular}{|c|c|c|c|c|}
\hline Caso & Blastos & Pró-mielócitos & $\begin{array}{l}\text { Mielócitos, metamielócitos e } \\
\text { bastonetes }\end{array}$ & $\begin{array}{c}\text { Neutrófilos } \\
\text { maduros }\end{array}$ \\
\hline Vn-236-00 & 5 & - & + & + \\
\hline Vn-235-01 & 9 & + & ++ & ++ \\
\hline Vn-331-02 & 8 & - & + & + \\
\hline Vn-210-04 & 6 & + & ++ & + \\
\hline Vn-256-04 & 8 & - & + & + \\
\hline Vn-164-06 & 5 & + & +++ & ++ \\
\hline Vn-327-11 & 4 & - & + & + \\
\hline Vn-312-12 & 11 & - & + & + \\
\hline Vn-337-14 & 9 & + & ++ & ++ \\
\hline Vn-343-15 & 6 & - & + & + \\
\hline Vn-085-16 & 12 & + & ++ & +++ \\
\hline Vn-208-16 & 9 & - & ++ & ++ \\
\hline Vn-384-16 & 10 & + & +++ & ++ \\
\hline Vn-065-17 & 8 & - & ++ & + \\
\hline Vn-067-17 & 8 & - & + & + \\
\hline Vn-172-17 & 9 & + & + & + \\
\hline
\end{tabular}

*Escala de volume ocupado por cada tipo ou grupamento celular do compartimento mieloide na medula óssea, sendo + mínima quantidade de células, ++ pequena quantidade de células, +++ moderada quantidade de células, ++++ grande quantidade de células, +++++ máxima quantidade de células.

esparsa, tinham morfologia típica, com citoplasma abundante e marcadamente basofílico, e núcleo rechaçado para periferia e formado por cromatina nuclear com "padrão em roda de carroça". Alguns plasmócitos tinham grânulos eosinofílicos e de volumes distintos (mas sempre $\leq 2 \mu \mathrm{m}$ de diâmetro), morfologicamente consistentes com corpúsculos de Russel. Essas células foram identificadas como células de Mott. Outros tinham citoplasma intensamente eosinofílico ("células em chama").

Na imuno-histoquímica, em todos os casos testados houve imunomarcação acentuada anti-mieloide utilizando anticorpo anti-MAC 387. Essa imunomarcação era vista apenas nas áreas de medula óssea ativa e envolvia a maior parte das células nucleadas (Fig.7). Quanto ao padrão morfológico de 


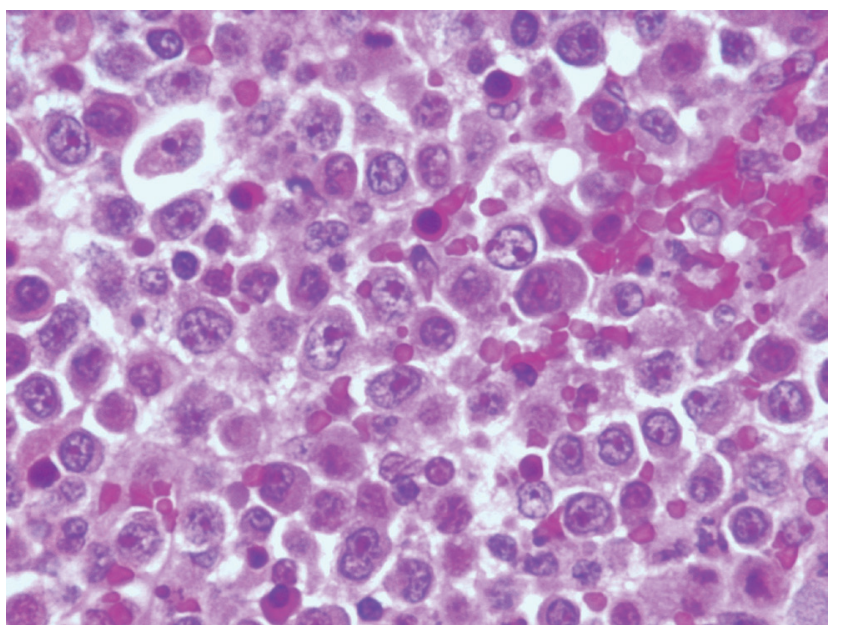

Fig.2. Peritonite infecciosa felina, medula óssea, gato. Maior aumento da figura anterior demonstrando grande quantidade de blastos. HE, obj.40x.

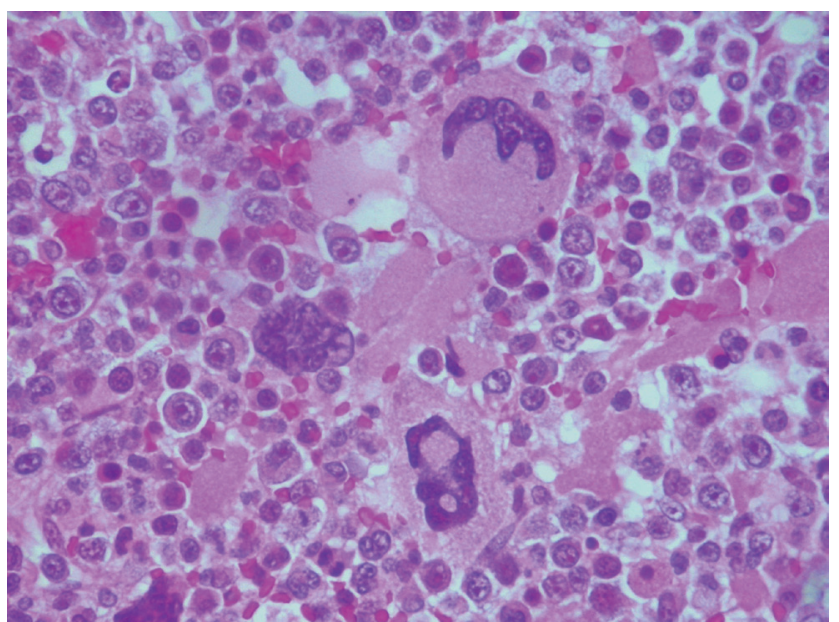

Fig.5. Peritonite infecciosa felina, medula óssea, gato. Megacariócitos dislobulado e com núcleos em forma de chifre de veado. HE, obj.20x.

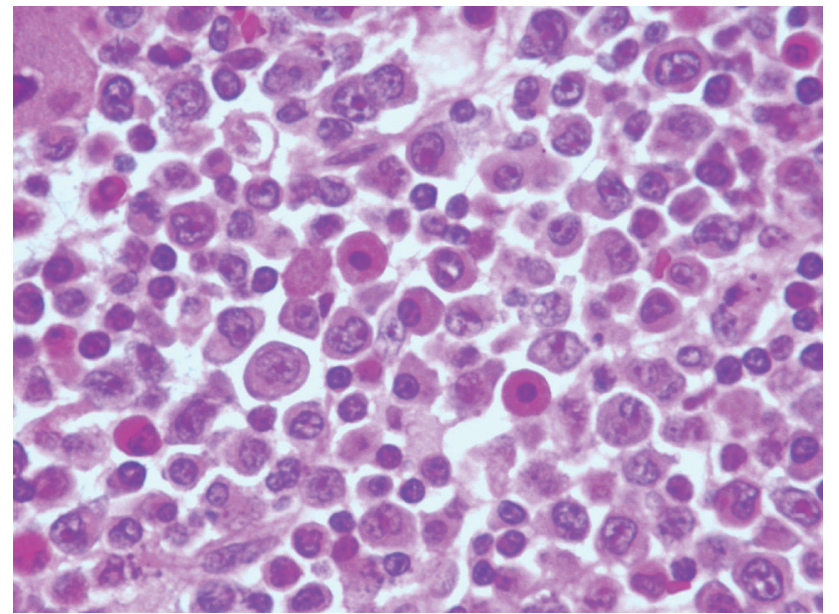

Fig.6. Peritonite infecciosa felina, medula óssea, gato. Pequena quantidade plasmócitos em meio ao tecido mieloide, incluindo "células em chama". HE, obj.20x.

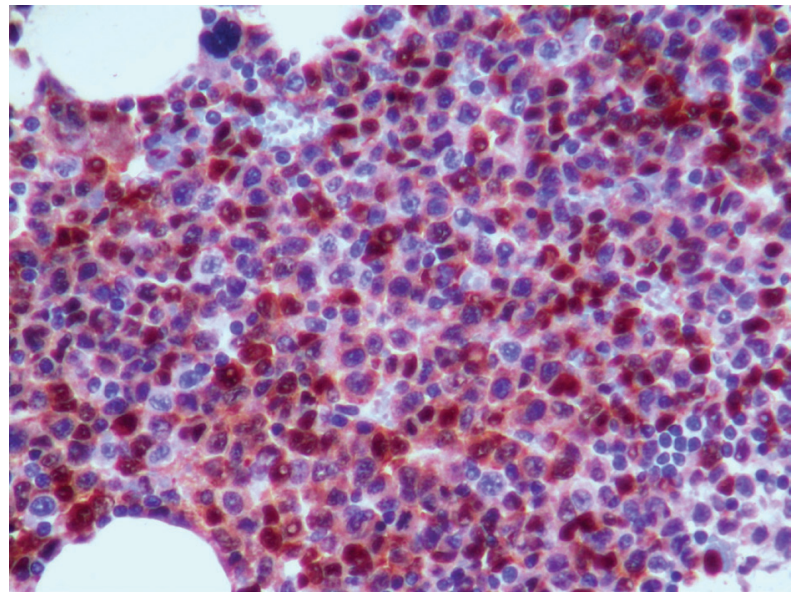

Fig.7. Peritonite infecciosa felina, medula óssea, gato. Imunomarcação para MAC demonstrando que o tecido mieloide é o responsável pela alta celularidade tecidual. Imuno-histoquímica, obj.10x. 
imunomarcação, as células positivas possuíam citoplasma finamente granular e castanho, com maior intensidade na região próxima à membrana nuclear, o que dava, por vezes, uma impressão de marcação nuclear (Fig.8). Imunomarcação anti-linfoide foi observada com anticorpo anti-CD79 $\alpha$ cy, mas não com anticorpo CD3. Essa imunomarcação era vista apenas nas áreas de medula óssea ativa e envolvia entre 1\% e 5\% das células nucleadas (Fig.9). Quanto ao padrão morfológico de imunomarcação, as células positivas possuíam citoplasma finamente granular e castanho e ausência de reatividade em uma "zona clara justanuclear", permitindo inclusive classificar a célula imunofenotipicamente como um plasmócito (Fig.10).

Pelo método de Perls, dois padrões de reação foram observados: 1) em um deles havia mínima quantidade de pontos azuis no citoplasma de alguns poucos macrófagos dispersos no tecido (Figs.11 e 12); 2) no outro havia acentuada quantidade de grânulos azuis de diferentes dimensões na totalidade de macrófagos no tecido (Fig.13 e 14). 0 grau de reação em cada caso pode ser visto no Quadro 3. Uma comparação neste mesmo quadro pode ser feita com o fígado (Figs.15 e 16), tanto em relação ao grau de reação como em quais células ocorreu (células de Kupffer e/ou hepatócitos).

Dos 16 gatos que tiveram suas medulas ósseas reavaliadas, em 12 foi possível recuperar os resultados dos hemogramas a partir da análise conjunta dos laudos de necropsia, das fichas clínicas e das requisições de necropsia. Quanto ao eritrograma $(n=12)$, havia anemia leve a moderada (hematócrito variou de 13 a 23\%) normocítica (VCM [volume corpuscular médio] variou de 41,9 a 52,4 fentolitros) normocrômica (CHCM [concentração de hemoglobina corpuscular média] variou de 31,5 a 34,4\%) em nove casos (75\%). Em nenhum desses casos havia qualquer menção a critérios de regeneração eritroide nos comentários. Quanto ao leucograma $(n=12)$, leucocitose leve (variou de 19.800 a 24.600 leucócitos $/ \mathrm{mm}^{3}$ de sangue) foi observada em três gatos (25\%). Nesses três e em mais outros três havia neutrofilia (50\%) leve (de 15.066 a 23.616 neutrófilos $/ \mathrm{mm}^{3}$ de sangue) e com desvio à esquerda em apenas um caso (8,3\%). Linfopenia moderada a acentuada (de 198 a 1.134 linfócitos $/ \mathrm{mm}^{3}$ de sangue), entretanto, foi um achado altamente prevalente, ocorrendo na totalidade dos casos (100\%). Monocitose só ocorreu em um caso $(8,3 \%)$. Quanto ao plaquetograma $(n=7)$, trombocitopenia foi observada em seis casos $(85,7 \%)$, sempre leve (variou de 78.000 a 282.000 plaquetas $/ \mathrm{mm}^{3}$ de sangue) e com VPM (volume plaquetário médio) normal para a espécie. Não foram observadas diferenças quanto à prevalência ou à intensidade dos achados hematológicos entre os casos de PIF úmida e seca. Os resultados dos hemogramas estão no Quadro 4.

\section{DISCUSSÃO}

Apesar da peritonite infecciosa felina (PIF) ser uma doença multissistêmica que cursa com anemia, estudos que mencionem lesões na medula óssea são escassos. Nos poucos artigos que abordam a avaliação anatomopatológica de órgãos linfohematopoiéticos, a atenção é dada principalmente ao tecido linfoide (Ward et al. 1974). 0 tecido hematopoiético não linfoide é raramente avaliado e, quando isso ocorre, quase sempre o objetivo é estudar a patogênese da chamada "anemia da PIF". Em 1971, Schalm publicou um artigo em que avaliou o sangue periférico de 35 gatos com PIF, demonstrando que 43\%

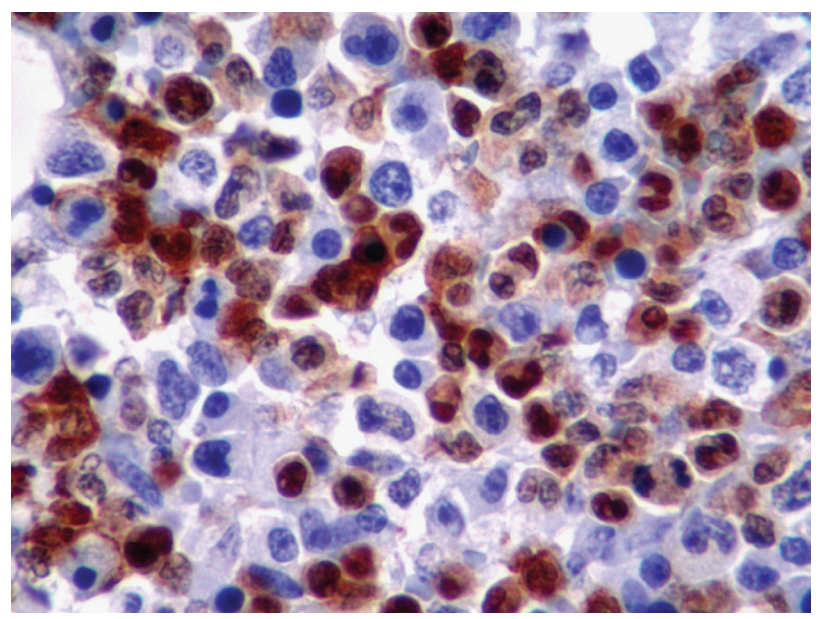

Fig.8. Peritonite infecciosa felina, medula óssea, gato. Precursores mieloides de linhagem granulocítica, principalmente mielócitos, metamielócitos e bastonetes com citoplasma fortemente imunomarcado. Imuno-histoquímica, obj.40x.

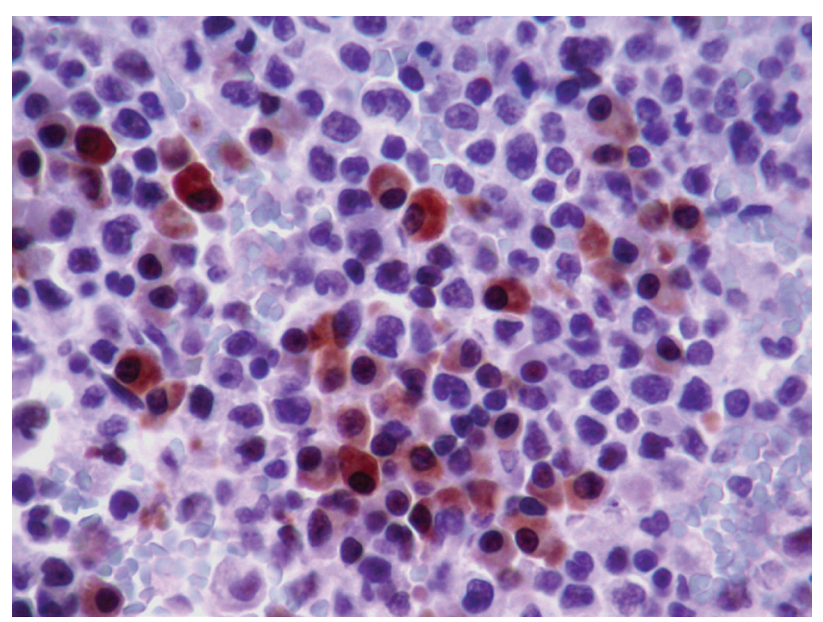

Fig.9. Peritonite infecciosa felina, medula óssea, gato. Imunomarcação para CD79 $\alpha$ cy evidenciando células B, principalmente plasmócitos. Imuno-histoquímica, obj.20x.

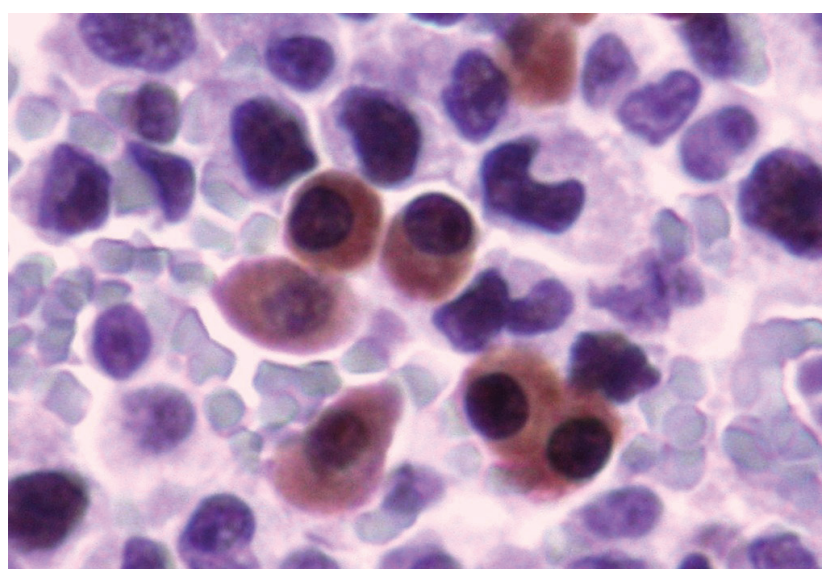

Fig.10. Peritonite infecciosa felina, medula óssea, gato. Plasmócitos com padrão de imunomarcação caracterizado por citoplasma intensa e homogeneamente marrom-escuro. Imuno-histoquímica, obj.40x. 


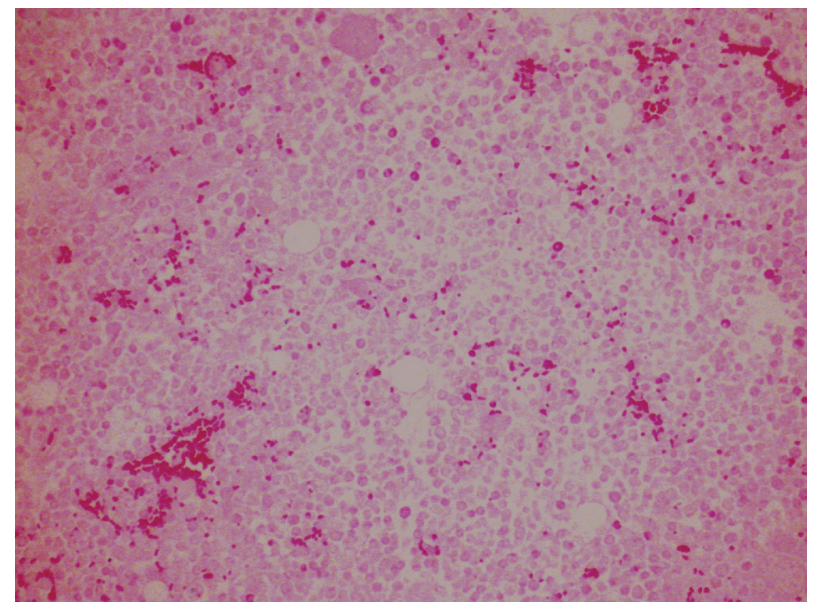

Fig.11. Peritonite infecciosa felina, medula óssea, gato. Ausência de reatividade azul prussiana. Reação de Perls, obj.10x.

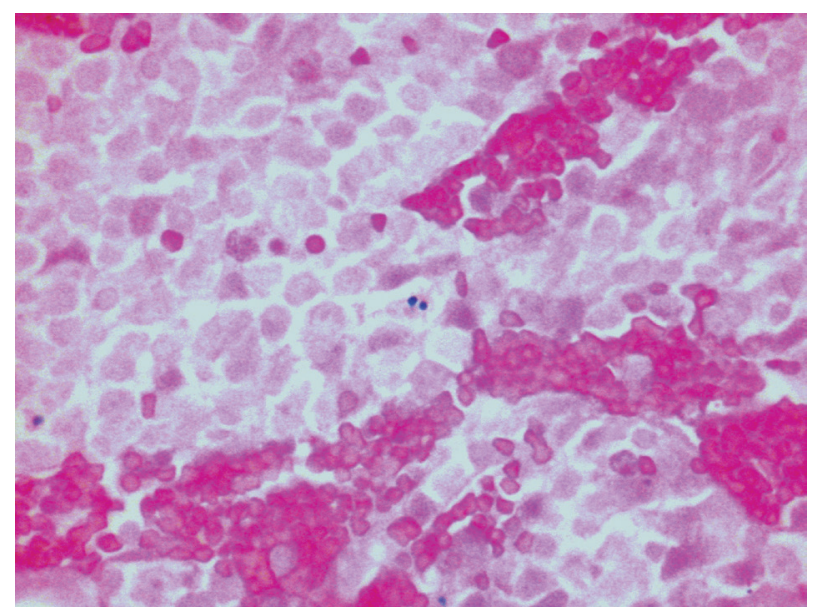

Fig.12. Peritonite infecciosa felina, medula óssea, gato. Maior aumento da figura anterior demonstrando ínfima quantidade de pigmento azul prussiano no citoplasma de um único macrófago. Reação de Perls, obj.20x.

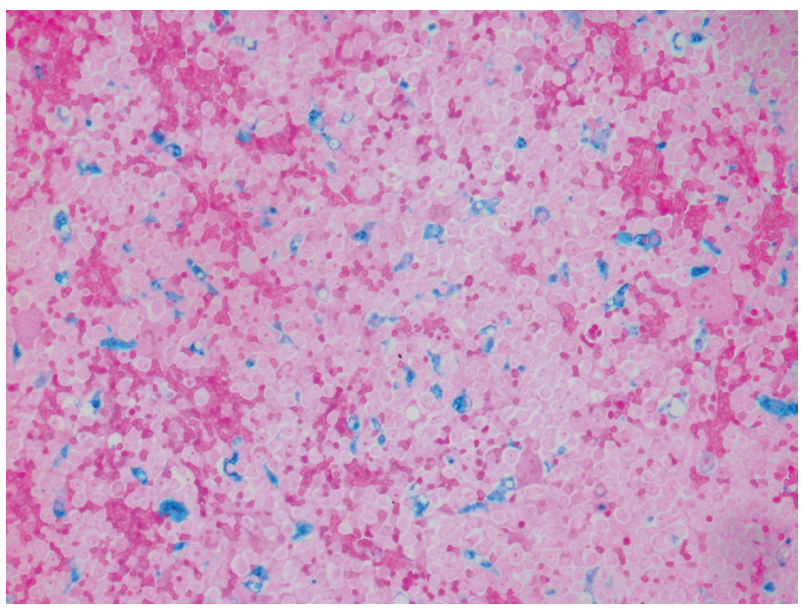

Fig.13. Peritonite infecciosa felina, medula óssea, gato. Padrão aleatório de reatividade azul prussiana. Reação de Perls, obj.10x.

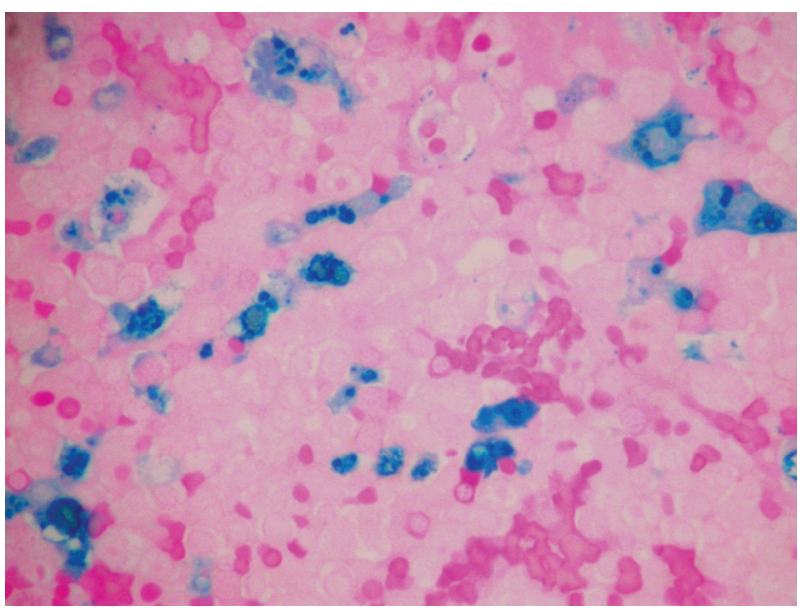

Fig.14. Peritonite infecciosa felina, medula óssea, gato. Maior aumento da figura anterior demonstrando grande quantidade de pigmento azul prussiano no citoplasma de macrófagos. Reação de Perls, obj.20x.

Quadro 3. Níveis férricos teciduais de gatos com peritonite infecciosa felina

\begin{tabular}{|c|c|c|c|c|c|}
\hline Caso & Forma & Macrófagos na MO & Precursores eritroides na MO & Células de Kupffer & Hepatócitos \\
\hline Vn-236-00 & úmida & $+*$ & - & + & - \\
\hline Vn-235-01 & seca & - & - & - & - \\
\hline Vn-331-02 & úmida & + & - & - & - \\
\hline Vn-210-04 & úmida & - & - & - & - \\
\hline Vn-256-04 & úmida & - & - & + & - \\
\hline Vn-164-06 & seca & - & - & - & - \\
\hline Vn-327-11 & úmida & + & - & + & - \\
\hline Vn-312-12 & úmida & - & - & - & - \\
\hline Vn-337-14 & seca & + & - & $\mathrm{NR}^{1}$ & NR \\
\hline Vn-343-15 & úmida & - & - & + & - \\
\hline Vn-085-16 & seca & + & - & +++ & + \\
\hline Vn-208-16 & seca & + & - & + & - \\
\hline Vn-384-16 & seca & ++ & - & +++ & + \\
\hline Vn-065-17 & úmida & - & - & ++ & - \\
\hline Vn-067-17 & mista & - & - & + & - \\
\hline Vn-172-17 & úmida & - & - & - & - \\
\hline
\end{tabular}

* Escala de ferro tecidual, sendo - ausência de ferro detectável pelo método de Perls, + pequena quantidade de células com ferro detectável pelo método de Perls, ++ moderada quantidade de células com ferro detectável pelo método de Perls, +++ acentuada quantidade de células com ferro detectável pelo método de Perls. 1NR: não realizado. 


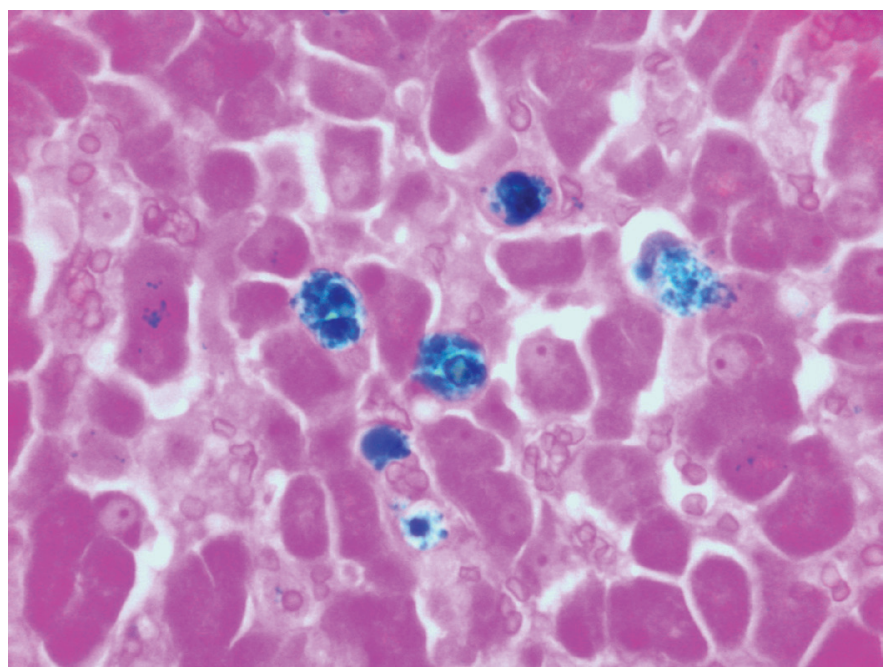

Fig.15. Peritonite infecciosa felina, fígado, gato. Múltiplas células de Kupffer com citoplasma repleto de conteúdo azul prussiano, confirmando uma reação muito positiva para ferro férrico. Note a leve reação em hepatócitos. Reação de Perls, obj.20x.

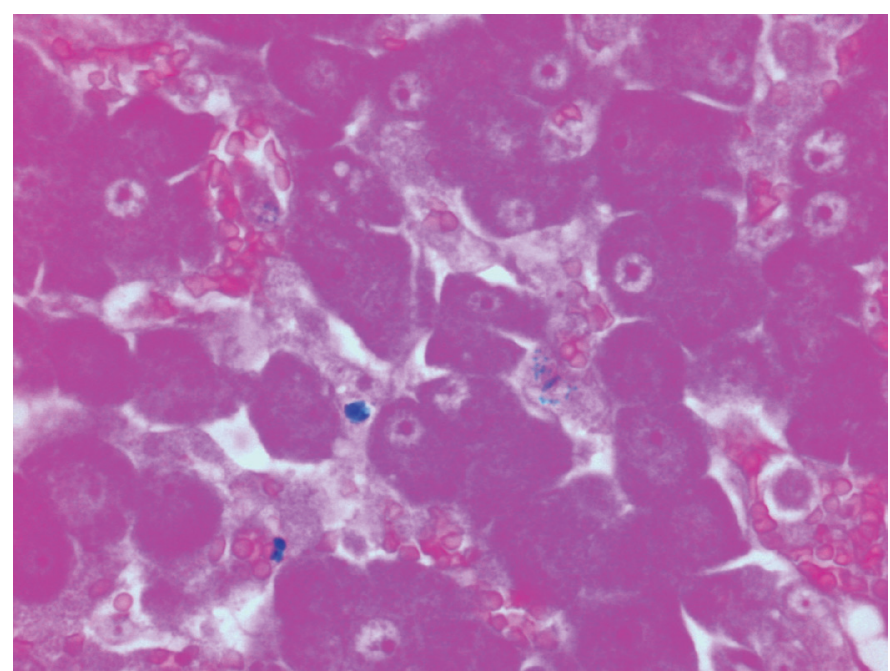

Fig.16. Peritonite infecciosa felina, fígado, gato. Algumas células de Kupffer com citoplasma com pouco conteúdo azul prussiano, confirmando uma reação fracamente positiva para ferro férrico. Note ausência de reação em hepatócitos. Reação de Perls, obj.20x.

Quadro 4. Resultados dos hemogramas de gatos com peritonite infecciosa felina

\begin{tabular}{|c|c|c|c|c|c|c|c|c|c|c|c|c|c|}
\hline Caso & Forma & Erit. $^{b}$ & $\mathrm{Hb}^{\mathrm{c}}$ & $\mathrm{Ht}^{\mathrm{d}}$ & $\mathrm{VCM}^{\mathrm{e}}$ & $\mathrm{CHCM}^{\mathrm{f}}$ & Leuc. $^{g}$ & Neu. $^{\mathrm{h}}$ & Bas. $^{\mathrm{i}}$ & Linf. $^{j}$ & Mon. ${ }^{k}$ & Eos. ${ }^{1}$ & Plaq. ${ }^{\mathrm{m}}$ \\
\hline Vn-236-00 & úmida & 4,2 & 7,1 & 22 & 52,4 & 32,3 & 21.800 & 19.620 & 218 & 1.090 & 654 & 218 & $\mathrm{NR}^{\mathrm{n}}$ \\
\hline Vn-235-01 & seca & 2,9 & 4,5 & 14 & 48,3 & 32,1 & 16.200 & 15.066 & 0 & 1.134 & 0 & 0 & NR \\
\hline Vn-331-02 & úmida & 4,5 & 7,5 & 23 & 51,1 & 32,6 & 17.800 & 16.554 & 178 & 712 & 178 & 178 & NR \\
\hline Vn-210-04 & úmida & 6,5 & 8,5 & 27 & 41,6 & 31,5 & 10.300 & 9.270 & 0 & 824 & 206 & 0 & NR \\
\hline Vn-256-04 & úmida & 3,3 & 5,5 & 16 & 48,5 & 34,4 & 7.500 & 7.050 & 75 & 225 & 75 & 75 & NR \\
\hline Vn-312-12 & úmida & 5,2 & 7,9 & 23 & 44,2 & 34,3 & 9.500 & 7.980 & 0 & 665 & 475 & 380 & 282 \\
\hline Vn-337-14 & seca & 4,7 & 6,3 & 20 & 42,6 & 31,5 & 19.000 & 18.050 & 570 & 380 & 0 & 0 & 174 \\
\hline Vn-343-15 & úmida & 3,6 & 5,5 & 16 & 44,4 & 34,4 & 400 & 128 & 8 & 224 & 32 & 8 & 111 \\
\hline Vn-384-16 & seca & 8,4 & 13,2 & 43 & 51,2 & 30,7 & 14.000 & 11.200 & 420 & 420 & 1.680 & 280 & 260 \\
\hline Vn-065-17 & úmida & 7,8 & 11,3 & 36 & 46,1 & 31,4 & 19.800 & 18.810 & 198 & 198 & 594 & 0 & 150 \\
\hline Vn-067-17 & mista & 5,6 & 7,9 & 23 & 41,1 & 34,3 & 24.600 & 23.616 & 246 & 492 & 246 & 0 & 78 \\
\hline Vn-172-17 & úmida & 3,1 & 4,1 & 13 & 41,9 & 31,5 & 11.700 & 10.179 & 0 & 936 & 468 & 117 & 355 \\
\hline $\mathrm{VR}^{\mathrm{a}}$ & & $5-10$ & 8-15 & $24-45$ & $39-55$ & $30-36$ & $5.500-19.500$ & $2.500-12.500$ & $\leq 300$ & $1.500-7.000$ & $\leq 850$ & $\leq 1.500$ & $300-800$ \\
\hline
\end{tabular}

${ }^{\mathrm{a}} \mathrm{VR}=$ valores de referencia, ${ }^{\mathrm{b}}$ Erit. = eritrócitos (valores em x10 $/ \mathrm{mm}^{3}$ de sangue), ${ }^{\mathrm{c}} \mathrm{Hg}=$ hemoglobina (valores em g/dL), ${ }^{\mathrm{d}} \mathrm{Ht}=\mathrm{hematócrito}($ valores

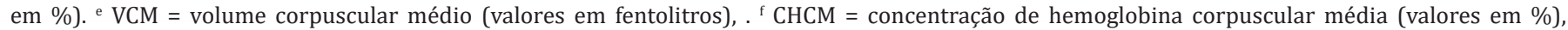

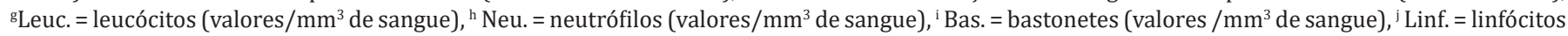

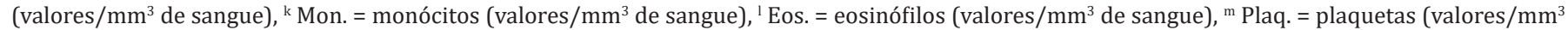
de sangue), ${ }^{\mathrm{n}} \mathrm{NR}=$ Não realizado.

apresentavam anemia normocítica normocrômica, concluindo que a anemia se devia à eritrogênese diminuída (Schalm 1971). Anos mais tarde, outros autores atribuíram essa diminuição na produção de eritrócitos à escassez de ferro medular disponível para síntese da hemoglobina, ou seja, tratava-se de "anemia da inflamação". Assim, para quase a totalidade dos autores, a anemia vista em casos de PIF é decorrente simplesmente desse clássico mecanismo do sequestro de ferro, típico das chamadas doenças crônicas (Stockham 2000). Entretanto, os achados observados em nossos casos demonstram que essa, talvez, não seja realmente a verdadeira patogênese, ou pelo menos a única. A medula óssea da maior parte dos casos de PIF, sendo todos os casos da forma úmida, não demonstrou nenhuma reserva de ferro. Os fragmentos de fígado desses mesmos casos, de forma semelhante, tinham apenas uma quantidade ínfima do mineral. Nos casos de evolução clínica mais prolongada, basicamente naqueles em que a apresentação foi considerada como seca, havia moderado ou acentuado acúmulo de ferro em macrófagos, o que pôde ser facilmente identificado pela reação de Perls. Com base nesses achados, descarta-se o clássico mecanismo proposto de sequestro de ferro como patogênese da anemia na PIF, ao menos na forma úmida da doença.

Desde que foi descoberta (Wolfe \& Griesemer 1966), a PIF nunca foi observada como uma doença em que algum comprometimento hematopoiético fosse suficientemente importante para ser mencionado dentro dos capítulos acerca da patologia do sistema hematopoiético dos principais livros de patologia veterinária. Da primeira descrição anatomopatológica de PIF (Wolfe \& Griesemer 1971) até os dias atuais, quase 
nada em relação a esse sistema foi reconhecido, com exceção do artigo de Ward et al. (1974), que refere necrose como lesão medular. Não apenas as lesões referentes à medula óssea, mas os próprios achados hematológicos, com exceção à anemia, vistos em gatos com PIF, são frequentemente negligenciados. A trombocitopenia é citada apenas em alguns livros (Feldman et al. 2000) e sua patogênese é apenas superficialmente comentada (Russell \& Grindem 2000). Para Boudreaux et al. (1990a, 1990b), gatos com PIF tornam-se trombocitopênicos devido à destruição plaquetária aumentada pela deposição de imunocomplexos na superfície plaquetária e/ou por consumo decorrente da coagulação intravascular disseminada (CID) desencadeada pela vasculite. Em relação à leucometria, no clássico estudo de Schalm (1971), 34/35 gatos com PIF apresentavam alterações nas contagens globais. Leucopenia e leucocitose devido à neutropenia e neutrofilia, respectivamente, ocorreram. Os parâmetros leucocitários mínimos e máximos foram 1.700 e 52.000 leucócitos $/ \mathrm{mm}^{3} \mathrm{de}$ sangue, respectivamente. A leucometria media e mediana foi de 18.000 e 12.800 leucócitos $/ \mathrm{mm}^{3}$ de sangue, respectivamente. 0 achado mais comum era neutrofilia com desvio à esquerda constituído basicamente por bastonetes. Leucopenia por neutropenia é incomum na PIF e aparentemente vista quase que apenas em um estádio terminal da doença (Horzinek \& Osterhaus 1979). Linfopenia é achado comum e descrito por basicamente todos os livros de clínica médica, infectologia e patologia clínica veterinária.

O aumento na proporção de blastos na medula óssea constitui um tipo de alteração que atualmente é incluída dentro do denominado "distúrbio progressivo". Esses distúrbios incluem hiperplasias, displasias (mielodisplasias) e neoplasias (leucemias mieloides agudas - LMAs e distúrbios mieloproliferativos crónicos - DMCs) (Fighera \& Graça 2016). Um aspecto fundamental na diferenciação citológica de hiperplasias para com displasias e neoplasias em uma avaliação da medula óssea refere-se muito mais à quantidade de cada uma das células do que a sua morfologia (Fighera 2014). Baseado nos critérios da OMS, o diagnóstico de hiperplasia é estabelecido quando a percentagem de blastos medulares é menor do que $6 \%$ do total de células nucleadas (TCN) em uma medula óssea com relação mieloide:eritroide (M:E) maior do que um (Relação M:E>1). As síndromes mielodisplásicas (SMDs) e os DMCs, por sua vez, são diagnosticados quando os blastos perfazem mais do que $6 \%$, mas menos do que $20 \%$ do TCN. Por fim, para o diagnóstico de leucemia mieloide aguda (LMA) necessita haver $\geq 20 \%$ de blastos do TCN da medula óssea. Com base nesses parâmetros, muitos dos casos de PIF avaliados por nós (69\%), possuem critérios numéricos que permitem incluí-los como mielodisplasias. Adicionalmente, o compartimento megacariocítico demonstrou alguns achados qualitativos típicos de dismegacariocitopoiese em todos os casos. Tais casos não representam um processo proliferativo mielodisplásico verdadeiro, ou seja, uma SMD, como ocorre em gatos infectados pelo vírus da leucemia felina (FeLV), mas sim uma lesão mielodisplásica.

As SMDs ou síndromes dismielopoiéticas, também previamente denominadas como "leucemia refratária primária" e "anemia pré-leucêmica", constituem um conjunto inter-relacionado de distúrbios da medula óssea que se caracteriza por ter um desenvolvimento clonal anormal de células que proliferam e substituem gradativamente aquelas hematopoiéticas normais (Yawata 1998, Bain 2003). Tais células frequentemente pertencem a mais de uma linhagem celular, ou seja, mielodisplasia bilinhagem ou trilinhagem versus mielodisplasia monolinhagem; os compartimentos afetados podem ser mieloide (granulocítico/monocítico dismielopoiese), eritroide (diseritropoiese) e/ou megacariocítico (dismegacariocitopoiese) (Brunning et al. 2001). Atualmente, segundo a OMS, as SMD incluem: SMD com displasia monolinhagem, SMD com displasia multilinhagem, SMD com excesso de blastos (previamente anemia refratária com excesso de blastos), SMD com sideroblastos em anel (previamente anemia refratária com sideroblasto em anel) e SMD não classificadas. Em humanos, as principais lesões mielodisplásicas vistas em pacientes com SMD incluem: blastos com bastões de Auer ou com grânulos gigantes (pseudo-anomalia de Chédiak-Higashi), pró-mielócitos hipergranulares, ausência de neutrófilos maduros, aumento na população de eosinófilos, basófilos e mastócitos (incluindo atipia de mastócitos), eosinófilos com cristais de Charcot-Leyden no citoplasma, alteração megaloblastoide em normoblastos, normoblastos binucleados ou multinucleados, apoptose de normoblastos, micromegacariócitos mononucleares ou binucleares (" $d$ warf megacaryocyte"), megacariócitos hipolobulados, multilobulados e dislobulados, incluindo aqueles com núcleos botrioides (Bain 2003). Tais achados em gatos são semelhantes (Valli et al. 2001, McManus 2005, Valli 2007)

As expressões "alterações dismielopoiéticas reativas" (ADR) ou "achados mielodisplásicos reativos" (AMR), do inglês "myelodysplastic features" (MDF), têm sido utilizadas para descrever uma medula óssea hematopoiética ativa e altamente celular, caracterizada por grande quantidade de blastos, retardo maturativo do compartimento granulocítico, pleomorfismo de megacariócitos, atipia dos elementos mais imaturos do compartimento eritroide, infiltrados linfoides atípicos e plasmocitose (Vassallo \& Magalhães 2009). Essa lesão preenche critérios quantitativos e qualitativos para ser incluída como uma SMD, mas, devido sua natureza reacional à infecção viral, ao consumo de certos fármacos ou à exposição a tóxicos, tem sido tratada em separado. Apesar de pouco descrita em medicina veterinária, a MDF é bastante reconhecida em pacientes humanos, principalmente naqueles infectados pelo vírus da imunodeficiência humana (HIV), situação em que é chamada "mielopatia relacionada à AIDS", do inglês "AIDS-related myelopathy" (Thiele et al. 1996). Nesses casos, os pacientes não apresentam uma SMD verdadeira ou primária, mas sim uma hematopoiese displásica (Bain 2003). Entretanto, essa diferenciação é mais facilmente estabelecida na teoria do que na prática, pois os achados hematológicos do sangue periférico e da medula óssea são muito semelhantes, para não dizer idênticos.

No final da década de 1980, um grupo de patologistas estudando pacientes HIV positivos em diferentes estádios da infecção demonstrou que 94,4\% (17/18) apresentavam lesões na medula óssea interpretadas como displásicas (Delacrétaz etal. 1987). A partir deste estudo, a curiosidade acerca do comportamento morfológico da medula óssea de indivíduos com AIDS passou de simplesmente avaliar megacariócitos, para entender a patogênese da trombocitopenia (ZuckerFranklin et al. 1989), para estudos bem mais aprofundados neste tecido. Em 1992, um estudo pioneiro atentou, pela primeira vez internacionalmente, para a similaridade entre 
achados histopatológicos observados na medula óssea de indivíduos com AIDS, principalmente em relação ao compartimento megacariocítico, para com aqueles utilizados como critérios no diagnóstico das SMDs (Thiele et al. 1992). Neste mesmo ano (Marche et al. 1992), e um ano antes (Diebold et al. 1991), outros dois artigos publicados fora da França, ambos com pouco aprofundamento, demonstrariam que a medula óssea de pacientes HIV positivos em diferentes estádios da infecção era displásica em 74,4\%-78,8\% dos casos. Desde então, critérios têm sido descritos para estabelecer um diagnóstico diferencial de SMD em um indivíduo HIV positivo que esteja apenas desenvolvendo uma "mielopatia associada à infecção viral" (Kaloutsi et al. 1994, Thiele et al. 1997). Apesar de muitos anos terem se passado desde a descrição inicial, poucos estudos conseguiram estabelecer critérios morfológicos sólidos para essa diferenciação com base apenas na avaliação histopatológica (Katsarou et al. 2001, Sitalakshmi et al. 2003). Tais critérios incluem principalmente a ausência de micromegacariócitos e blastos com bastões de Auer, a escassez de eosinófilos e seus precursores, a não ocorrência de diseritropoiese sideroblástica e a inexistência de alteração megaloblastoide em normoblastos. Todas essas alterações displásicas não estiveram presentes nos 16 casos apresentados por nós, demonstrando que os achados mielodisplásicos vistos na PIF assemelham-se fortemente com aqueles que podem ser utilizados para diferenciar uma lesão mielodisplásica de um paciente humano HIV positivo de outro com SMD.

\section{CONCLUSÕES}

Os achados histopatológicos observados na medula óssea de gatos com peritonite infecciosa felina (PIF) permitem afirmar que, independentemente da apresentação clinicopatológica da doença (seca ou úmida), ocorre: 1) hiperplasia mieloide; 2) hipoplasia eritroide, nem sempre (forma úmida) associada ao acúmulo de ferro; 3 ) displasia megacariocítica (dismegacariocitopoiese) e 4) plasmocitose medular.

Esses achados, associados ao diagnóstico reconhecido da doença, permitem estabelecer que na PIF ocorre uma mielodisplasia muito semelhante àquela descrita em humanos infectados pelo HIV.

Possivelmente, essa lesão mielodisplásica é a principal responsável pelos achados hematológicos, como anemia e trombocitopenia arregenerativas, vistos na PIF.

\section{REFERÊNCIAS}

Addie D.D. 2015. Infecção pelo coronavírus felino, p.95-112. In: Greene C.E. (Ed.), Doenças Infecciosas em Cães e Gatos. 4르 ed. Guanabara Koogan, Rio de Janeiro.

Bain B.J. 2003. Diagnóstico em Leucemias. 2ª ed. Revinter, Rio de Janeiro. 171p.

Boudreaux M.K., Weiss R.C., Toivio-Kinnucan M. \& Spano J.S. 1990a. Potentiation of platelet responses in vitro by feline infectious peritonitis virus. Vet. Pathol. 27(4):261-268. <http://dx.doi.org/10.1177/030098589002700407> $<$ PMid:2144930>

Boudreaux M.K., Weiss R.C., Toivio-Kinnucan M., Cox N. \& Spano J.S. 1990b. Enhanced platelet reactivity in cats experimentally infected with feline infectious peritonitis virus. Vet. Pathol. 27(4):269-273. <http://dx.doi. org/10.1177/030098589002700408><PMid:2169665>

Brunning R.D., Bennett J.M., Flandrin G., Matutes E., Head D., Vardiman J.W. \& Harris N.L. 2001. Myelodysplastic syndromes: introduction, p.63-67.
In: Jaffe E.S., Harris N.L., Stein H. \& Vardiman J.W. (Eds), World Health Organization Classification of Tumors. Pathology and Genetics of Tumours of Haematopoietic and Lymphoid Tissues. IARC Press, Lyon.

Delacrétaz F., Schmidt P.M., Piguet D., Bachmann F. \& Costa J. 1987. Histopathology of myelodysplastic syndromes. The FAB classification (proposals) applied to bone marrow biopsy. Am. J. Clin. Pathol. 87(2):180-186. <http://dx.doi. org/10.1093/ajcp/87.2.180> <PMid:3812349>

Diebold J., Tabbara W., Marche C., Audouin J. \& Le Tourneau A. 1991. Bone marrow changes at several stages of HIV infection, studied on bone marrow biopsies in 85 patients. Arch. Anat. Cytol. Pathol. 39(4):137-146. $<$ PMid:1755664>

Feldman B.F., Zinkl J.G. \& Jain N.C. 2000. Schalm's Veterinary Hematology. 5th ed. Lippincott Williams and Wilkins, Baltimore. 1344p.

Fighera R.A. 2014. Mielograma, p.120-145. In: Grandi F., Orsini H. \& Dourado L. (Eds), Citopatologia Veterinária. MedVet, São Paulo.

Fighera R.A. \& Graça D.L. 2016. Sistema hematopoiético, p.311-405. Santos R.L. \& Alessi A.C. (Eds), Patologia Veterinária. $2^{a}$ ed. Roca, Rio de Janeiro.

Horzinek M.C. \& Osterhaus A.D. 1979. The virology and pathogenesis of feline infectious peritonitis, brief review. Arch Virol. 59(1/2):1-15.<http:// dx.doi.org/10.1007/BF01317889><PMid:218528>

Jain N.C. 1986. Schalm's Veterinary Hematology. 4th ed. Lea and Febiger, Philadelphia.

Kaloutsi V., Kohlmeyer U., Maschek H., Nafe R., Choritz H., Amor A. \& Georgii A 1994. Comparison of bone marrow and hematologic findings in patients with human immunodeficiency virus infection and those with myelodysplastic syndromes and infectious diseases. Am. J. Clin. Pathol. 101(2):123-129. <http://dx.doi.org/10.1093/ajcp/101.2.123><PMid:8116565>

Katsarou O., Terpos E., Patsouris E., Peristeris P., Viniou N., Kapsimali V. \& Karafoulidou A. 2001. Myelodysplastic features in patients with long-term HIV infection and haemophilia. Haemophilia 7(1):47-52. <http://dx.doi. org/10.1046/j.1365-2516.2001.00445.x><PMid:11136381>

Marche C., Tabbara W. \& Matthiessen L. 1992. The bone marrow in human HIV infection. A bioptic study of 125 cases. Ann. Med. Interne, Paris. 143(3):191-197. <PMid:1524353>

McManus P.M. 2005. Classification of myeloid neoplasms: a comparative review. Vet. Clin. Pathol. 34(3):189-212.<http://dx.doi.org/10.1111/j.1939165X.2005.tb00042.x><PMid:16134066>

Norris J.M., Bosward K.L., White J.D., Baral R.M., Catt M.J. \& Malik R. 2005 Clinicopathological findings associated with feline infectious peritonitis in Sydney, Australia: 42 cases (1990-2002). Aust. Vet. J. 83(11):666-673. <http://dx.doi.org/10.1111/j.1751-0813.2005.tb13044.x><PMid:16315663>

Riemer F., Kuehner K.A., Ritz S., Sauter-Louis C. \& Hartmann K. 2016. Clinical and laboratory features of cats with feline infectious peritonitis--a retrospective study of 231 confirmed cases (2000-2010). J. Feline Med. Surg. 18(4):348-356. <http://dx.doi.org/10.1177/1098612X15586209> $<$ PMid:26185109>

Russell K.E. \& Grindem C.B. 2000. Secondary thrombocytopenia, p.487-495 In: Feldman B.F., Zinkl J.G. \& Jain N.C. (Eds), Schalm's Veterinary Hematology. 5th ed. Lippincott Williams and Wilkins, Baltimore. 1344p.

Schalm O.W. 1971. Feline Infectious Peritonitis. Calif. Vet. 25:6-10.

Sitalakshmi S., Srikrishna A. \& Damodar P. 2003. Haematological changes in HIV infection. Indian J. Pathol. Microbiol. 46(2):180-183. <PMid:15022904>

Stockham S.L. 2000. Anemia associated with bacterial and viral infectious, p.163-168. In: Feldman B.F., Zinkl J.G. \& Jain N.C. (Eds), Schalm's Veterinary Hematology. 5th ed. Lippincott Williams and Wilkins, Baltimore.

Thiele J., Zirbes T.K., Bertsch H.P., Titius B.R., Lorenzen J. \& Fischer R. 1996. AIDS-related bone marrow lesions: myelodysplastic features or predominant inflammatory-reactive changes (HIV-myelopathy)? A comparative morphometric study by immunohistochemistry with special 
emphasis on apoptosis and PCNA-labeling. Anal. Cell Pathol. 11(3):141157. <PMid:8888951>

Thiele J., Zirbes T.K., Wiemers P., Lorenzen J., Kvasnicka H.M. \& Fischer R. 1997. Incidence of apoptosis in HIV-myelopathy, myelodysplastic syndromes and non-specific inflammatory lesions of the bone marrow. Histopathology 30(4):307-311. <http://dx.doi.org/10.1046/j.1365-2559.1997.d01-622. $\mathrm{x}><$ PMid:9147075>

Thiele J., Titius B.R., Quitmann H., Fischer R., Salzberger B., Dienemann D. \& Stein H. 1992. Megakaryocytopoiesis in bone marrow biopsies of patients with acquired immunodeficiency syndrome (AIDS): an immunohistochemical and morphometric evaluation with special emphasis on myelodysplastic features and precursor cells. Pathol. Res. Pract. 188(6):722-728.<http:// dx.doi.org/10.1016/S0344-0338(11)80168-8> <PMid:1437834>

Tsai H.Y., Chueh L.L., Lin C.N. \& Su B.L. 2011. Clinicopathological findings and disease staging of feline infectious peritonitis: 51 cases from 2003 to 2009 in Taiwan. J. Feline Med. Surg. 13(2):74-80. <http://dx.doi.org/10.1016/j. jfms.2010.09.014><PMid:21216644>

Uzal F.A., Plattner B.L. \& Hostetter J.M. 2016. Alimentary system, 1-257. In: Maxie M.G. Jubb, Kennedy, and Palmer's Pathology of Domestic Animals. 6th ed. Elsevier, St Louis. <http://dx.doi.org/10.1016/B978-0-70205318-4.00007-3>

Valli V.E. 2007. Veterinary Comparative Hematopathology. Blackwell Publishing, Oxford. 558p. <http://dx.doi.org/10.1002/9780470344545>.
Valli V.E., Jacobs R.M., Parodi A.L., Vernau W. \& Moore P.F. 2001. Histological Classification of Hematopoietic Tumors of Domestic Animals. 2nd ed. WHO/AFIP, Washington, DC.

Vassallo J. \& Magalhães S.M.M. 2009. Síndromes mielodisplásicas e mielodisplásicas/mieloproliferativas. Revta Bras. Hematol. Hemoter. 31(4):267-272. <http://dx.doi.org/10.1590/S1516-84842009005000062>

Ward J.M., Gribble D.H. \& Dungworth D.L. 1974. Feline infectious peritonitis: experimental evidence for its multiphasic nature. Am. J. Vet. Res. 35(10):12711275. <PMid:4422322>

Wolfe L.G. \& Griesemer R.A. 1966. Feline infectious peritonitis. Pathol. Vet. 3(3):255-270. <http://dx.doi.org/10.1177/030098586600300309> $<$ PMid:5958991>

Wolfe L.G. \& Griesemer R.A. 1971. Feline infectious peritonitis: review of gross and histopathologic lesions. J. Am. Vet. Med. Assoc. 158(6):987-997. <PMid:5103508>

Yawata Y. 1998. Atlas de Doenças Hematológicas: citologia e histologia. Manole, São Paulo.

Zucker-Franklin D., Termin C.S. \& Cooper M.C. 1989. Structural changes in the megakaryocytes of patients infected with the human immune deficiency virus (HIV-1). Am. J. Pathol. 134(6):1295-1303. <PMid:2757119> 